\title{
Nanoscale
}

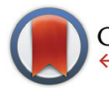

CrossMark

\&lick for updates

Cite this: Nanoscale, 2016, 8, 6278

Received 5th October 2015,

Accepted 23rd November 2015

DOI: $10.1039 / \mathrm{c} 5 \mathrm{nr} 06890 \mathrm{~h}$

www.rsc.org/nanoscale

\section{Polar-solvent-free colloidal synthesis of highly luminescent alkylammonium lead halide perovskite nanocrystals $\uparrow$}

\author{
Oleh Vybornyi, ${ }^{a, b}$ Sergii Yakunin ${ }^{a, b}$ and Maksym V. Kovalenko*a,b
}

A novel synthesis of hybrid organic-inorganic lead halide perovskite nanocrystals $\left(\mathrm{CH}_{3} \mathrm{NH}_{3} \mathrm{PbX}_{3}, \mathrm{X}=\mathrm{Br}\right.$ or $\left.\mathrm{I}\right)$ that does not involve the use of dimethylformamide or other polar solvents is presented. The reaction between methylamine and $\mathrm{PbX}_{2}$ salts is conducted in a high-boiling nonpolar solvent (1-octadecene) in the presence of oleylamine and oleic acid as coordinating ligands. The resulting nanocrystals are characterized by high photoluminescence quantum efficiencies of $15-50 \%$, outstanding phase purity and tunable shapes (nanocubes, nanowires, and nanoplatelets). Nanoplatelets spontaneously assemble into micrometer-length wires by face-to-face stacking. In addition, we demonstrate amplified spontaneous emission from thin films of green-emitting $\mathrm{CH}_{3} \mathrm{NH}_{3} \mathrm{PbBr}_{3}$ nanowires with low pumping thresholds of $3 \mu \mathrm{J} \mathrm{cm}$.

In the past few years, a great deal of attention has been devoted to hybrid lead halide semiconductors with a perovskite crystal structure, generically described by the formula $\mathrm{ABX}_{3}$ (where $\mathrm{A}$ is an organic or inorganic cation, $\mathrm{B}$ is a metal cation in the octahedral coordination state and $\mathrm{X}$ is a halogen anion). Such compounds exhibit outstanding optoelectronic properties in the form of thin films, microcrystals and bulk single-crystals. ${ }^{1-12}$ Initial motivation to investigate these materials arose from the demonstration of solution-cast, inexpensive solar cells with certified power conversion efficiencies exceeding 20\% (NREL efficiency chart, http://www.nrel. gov). ${ }^{13-15}$ Subsequently, other perovskite-based optoelectronic devices were demonstrated - sensitive solution-cast photodetectors operating in the visible, ${ }^{16-18}$ ultraviolet $^{19,20}$ and $\mathrm{X}$-ray ${ }^{21}$ spectral regions and light-emitting diodes ${ }^{22-26}$ - which

${ }^{a}$ ETH Zürich - Swiss Federal Institute of Technology Zürich, Vladimir Prelog Weg 1, CH-8093 Zürich, Switzerland. E-mail: mvkovalenko@ethz.ch

${ }^{b}$ Empa-Swiss Federal Laboratories for Materials Science and Technology, Laboratory for Thin Films and Photovoltaics, Überlandstrasse 129, CH-8600 Dübendorf, Switzerland

$\dagger$ Electronic supplementary information (ESI) available: Materials and methods, additional figures. See DOI: 10.1039/c5nr06890h all harness the unique defect-tolerant photophysics of these lead halide compounds.

The research landscape with respect to perovskites has also recently extended to the nanoscale, where quantum-size effects and the benefits of the colloidal state and shape engineering can be expected, stimulating efforts on the synthesis of supported and colloidal nanostructures of hybrid ${ }^{11,27-40}$ and fully inorganic perovskites. ${ }^{41,42}$ When compared to more conventional CdSe-based nanocrystals (NCs), perovskite NCs exhibit a number of unique properties such as high photoluminescence (PL) quantum yields (up to 90\%) without the need for additional electronic passivation by adding a widergap shell (e.g. CdSe/CdS and CdSe/ZnS NCs), and novel forms of chemical tunability such as by deliberately partial or complete anion-exchange reactions. ${ }^{36,42,43}$ Concerning hybrid organic-inorganic perovskite NCs, all reported colloidal procedures to date feature a common strategy, initially outlined by Pérez-Prieto et al.: ${ }^{29}$ the lead halide source and alkylammonium halide are dissolved in a "good" solvent (e.g. highly polar, that dissolves salts), usually dimethylformamide (DMF), and then injected into a "poor" (nonpolar) solvent such as toluene or 1-octadecene (ODE), containing surfactants, usually oleic acid (OA) and oleylamine (OAm). The subsequent formation of perovskite NCs proceeds primarily due to the lower solubility caused by the large amount of a nonpolar solvent. Highly polar DMF is also commonly used as the solvent for preparing supported, layered perovskite nanostructures. ${ }^{44,45}$

An alternative synthesis route, that is primarily based on ionic metathesis and does not involve polar solvents, was developed by our group for the synthesis of fully inorganic cesium lead halide $\mathrm{NCs}\left(\mathrm{CsPbX}_{3}\right.$ where $\mathrm{X}=\mathrm{Cl}$, Br or I). ${ }^{41,42}$ Cesium oleate as the $\mathrm{Cs}^{+}$source is injected into a solution of $\mathrm{PbX}_{2}$ in ODE containing long-chain capping ligands (an OAm/OA mixture). $\mathrm{PbX}_{2}$ thus serves as both the $\mathrm{Pb}^{2+}$ and $\mathrm{X}^{-}$source, releasing $\mathrm{Pb}$-oleate as a by-product. In this communication, we extend this ionic metathesis approach to hybrid perovskites, by replacing Cs-oleate with methylamine. The proton needed 
to form $\mathrm{CH}_{3} \mathrm{NH}_{3}{ }^{+}$is then provided by $\mathrm{OA}$, and the overall reaction is described as follows (see the ESI, $\uparrow$ for experimental details; $\mathrm{X}=\mathrm{Br}$ or I):

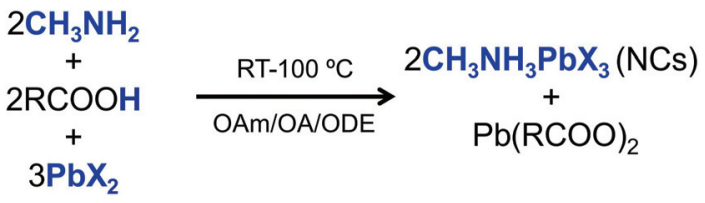

A $2 \mathrm{M}$ solution of methylamine $\left(\mathrm{CH}_{3} \mathrm{NH}_{2}\right)$ in tetrahydrofuran (THF) was combined with $\mathrm{OA}$ and injected into a vigorously stirring solution of $\mathrm{PbX}_{2}$ in ODE/OAm/OA mixture, causing the formation of NCs within seconds. This synthesis allows for the preparation of uniform, phase-pure colloidal NCs, completely free of any insoluble or microscopic products, with high reaction yield (40-70\%) and retention of chemical and colloidal integrity for at least three months. The same approach has not been successful in the case of $\mathrm{CH}_{3} \mathrm{NH}_{3} \mathrm{PbCl}_{3}$.

\section{$\mathrm{CH}_{3} \mathrm{NH}_{3} \mathrm{Pbl}_{3} \mathrm{NCs}$}

To achieve a high overall reaction yield, a minimal amount of the OAm/OA ligand mixture, just sufficient to solubilize $\mathrm{PbI}_{2}$, must be used. The $\mathrm{CH}_{3} \mathrm{NH}_{2}$ precursor solution is injected at $55{ }^{\circ} \mathrm{C}$, immediately producing a stable, dark-brown colloid of cubic $\sim 10 \mathrm{~nm}$ NCs. The UV-Vis absorption and photoluminescence (PL) spectra of $\mathrm{CH}_{3} \mathrm{NH}_{3} \mathrm{PbI}_{3}$ NCs (Fig. 1) exhibit an absorption band edge at $750 \mathrm{~nm}$, which is blue-shifted by $30-50 \mathrm{~nm}$ compared to the bulk material, ${ }^{10}$ due to quantumsize effects originating from the large exciton Bohr radius. PL quantum yields are typically $20-30 \%$. Importantly, the powder $\mathrm{X}$-ray diffraction (XRD) pattern can be indexed as pure tetragonal $\mathrm{CH}_{3} \mathrm{NH}_{3} \mathrm{PbI}_{3}$, with a line-width consistent with a mean particle size of $\sim 10 \mathrm{~nm}$ (Fig. 1c). Higher reaction temperatures of up to $100{ }^{\circ} \mathrm{C}$ lead to platelet-like $\mathrm{CH}_{3} \mathrm{NH}_{3} \mathrm{PbI}_{3}$ NCs (see Fig. S1 $\dagger$ ). By varying the ratio of OAm to OA, various other shapes such as smaller dot-like NCs and nanowire morphologies can be produced, but with suboptimal shapeand phase-uniformity (see Fig. S1†).

\section{$\mathrm{CH}_{3} \mathrm{NH}_{3} \mathrm{PbBr}_{3} \mathrm{NCs}$}

$\mathrm{PbBr}_{2}$ is observed to react slower, yet with nearly quantitative reaction yield. By adjusting the amount of OAm, this novel synthesis selectively yields either blue-emitting square nanoplatelet-like NCs (Fig. 2a, b and e) or green-luminescent nanowires (Fig. 2c, d and f). The XRD patterns can be indexed as pure orthorhombic $\mathrm{CH}_{3} \mathrm{NH}_{3} \mathrm{PbBr}_{3}$. These $35 \pm 5 \mathrm{~nm}$ square-shaped nanoplatelets exhibit an absorption peak at $\sim 450 \mathrm{~nm}$ and a single PL emission peak at $465 \mathrm{~nm}$, with a quantum yield (QY) of $18 \%$ and a full width at half maximum (FWHM) of $19 \mathrm{~nm}$. $\mathrm{CH}_{3} \mathrm{NH}_{3} \mathrm{PbBr}_{3}$ nanowires $\left(10 \times 100 \mathrm{~nm}^{2}\right)$ exhibit a narrow $\mathrm{PL}$ emission peak at $532 \mathrm{~nm}$, with a QY of 15\% and a FWHM of $22 \mathrm{~nm}$. Bright emission is also retained in the solid state, as can be seen for thin films of nanoplatelets and nanowires encapsulated between two plastic films and stored in air for several months (Fig. 2e and f, taken under ultraviolet illumination, $\lambda=365 \mathrm{~nm})$.

The formation of layered lead bromide perovskites, closest analogues to our nanoplatelets, was a subject of numerous recent studies. ${ }^{26,28,32,37,46-49}$ In such structures, optical properties are largely determined by the quantum confinement caused by small thicknesses of just a few nanometers. XRD experiments confirm that the individual colloidal nanoplatelets comprise the perovskite $\mathrm{CH}_{3} \mathrm{NH}_{3} \mathrm{PbBr}_{3}$ structure and, from TEM, they are $\sim 5 \mathrm{~nm}$ in thickness. Right after synthesis, $\mathrm{CH}_{3} \mathrm{NH}_{3} \mathrm{PbBr}_{3}$ nanoplatelets form stable colloidal solutions in toluene. TEM samples obtained from highly dilute samples illustrate separated, flat-lying platelets (see Fig. 3). Upon
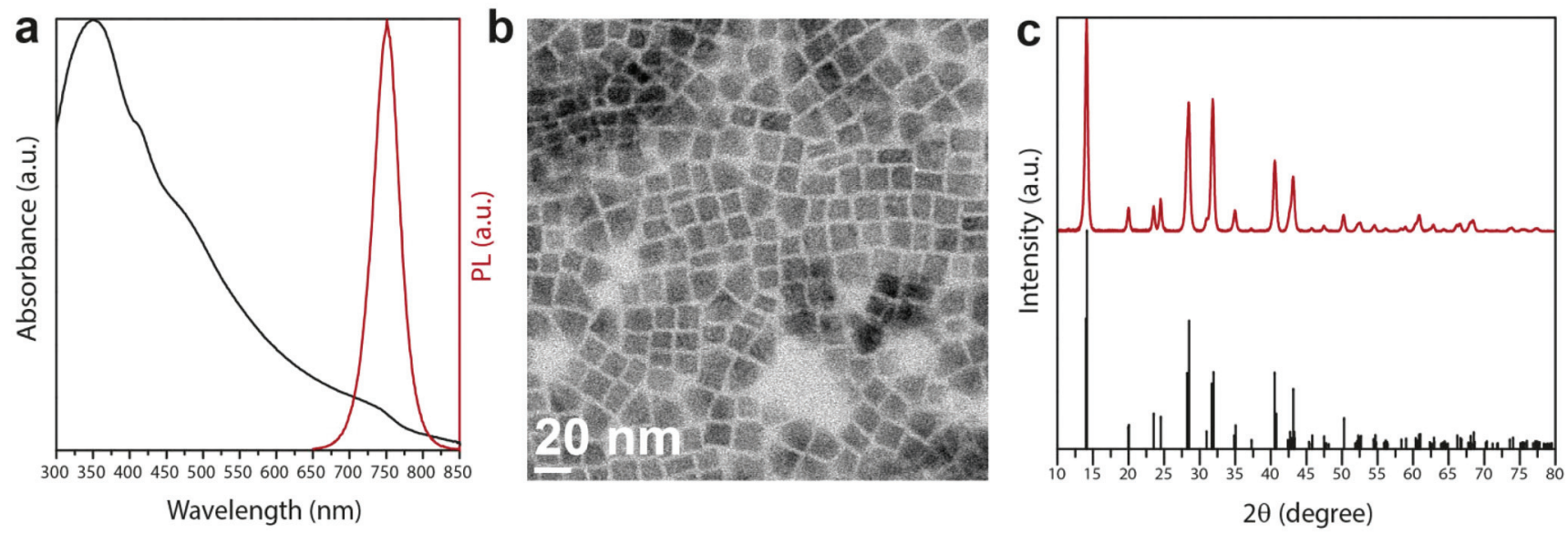

Fig. 1 Colloidal $\mathrm{CH}_{3} \mathrm{NH}_{3} \mathrm{Pbl}_{3} \mathrm{NCs}$ : (a) optical absorption and PL spectra measured in toluene, (b) transmission electron microscopy (TEM) image and (c) powder X-ray diffraction (XRD) pattern (measured, red), along with the simulated pattern of bulk, tetragonal $\mathrm{CH}_{3} \mathrm{NH}_{3} \mathrm{Pbl}{ }_{3}$ from the ICSD database (card number 250739, black). 

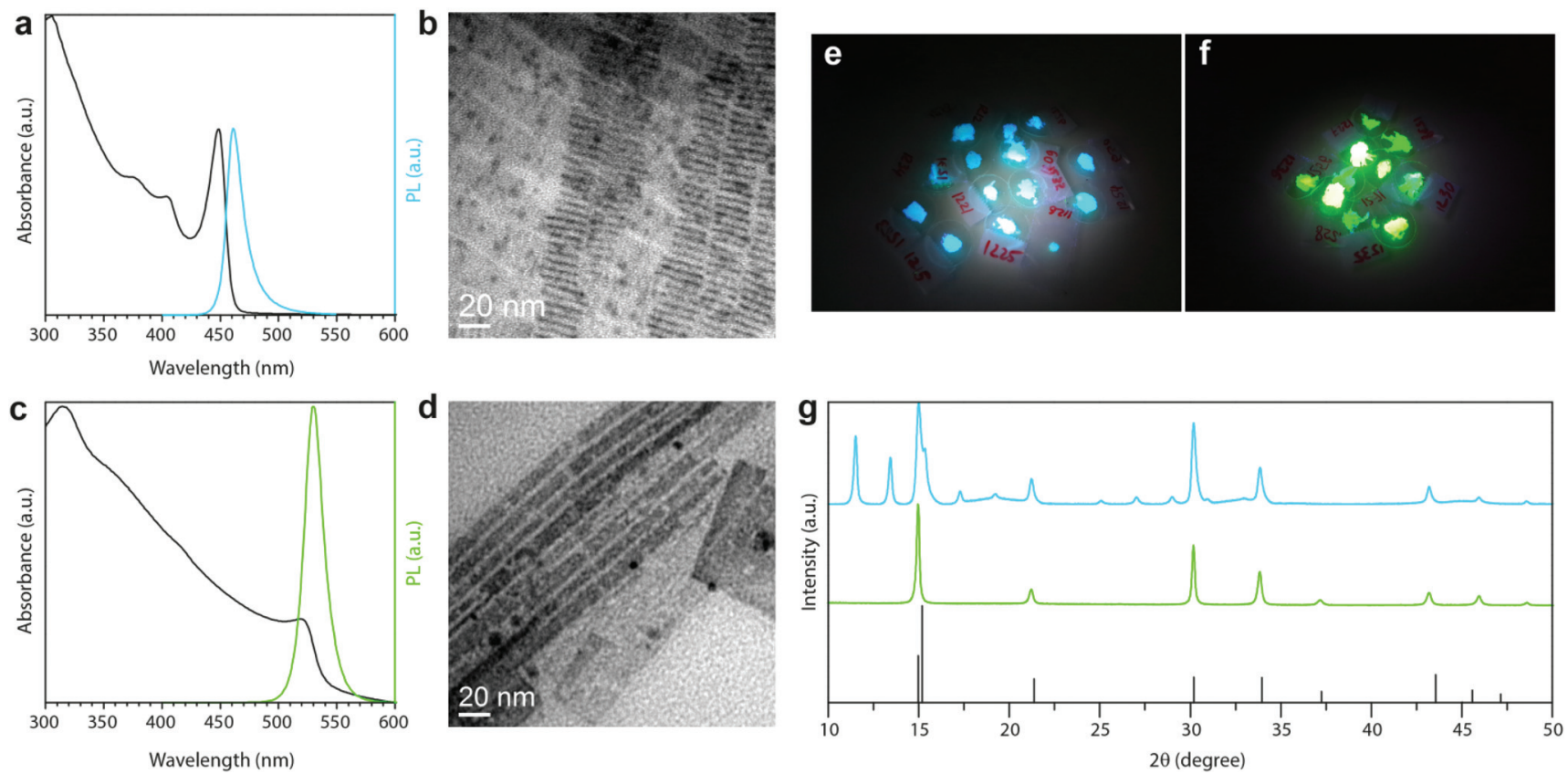

Fig. 2 Colloidal $\mathrm{CH}_{3} \mathrm{NH}_{3} \mathrm{PbBr}_{3} \mathrm{NCs}$ (nanoplatelets and nanorods): (a, c) optical absorption and PL spectra measured in toluene; (b, d) TEM images; $(\mathrm{e}, \mathrm{f})$ photographs of thin films of blue-emitting nanoplatelets and green-emitting nanorods, taken under UV radiation; (g) XRD patterns (measured, blue and green) along with the simulated pattern of bulk, orthorhombic $\mathrm{CH}_{3} \mathrm{NH}_{3} \mathrm{PbBr}_{3}$. Blue and green curves correspond to nanoplatelets and nanorods, respectively.
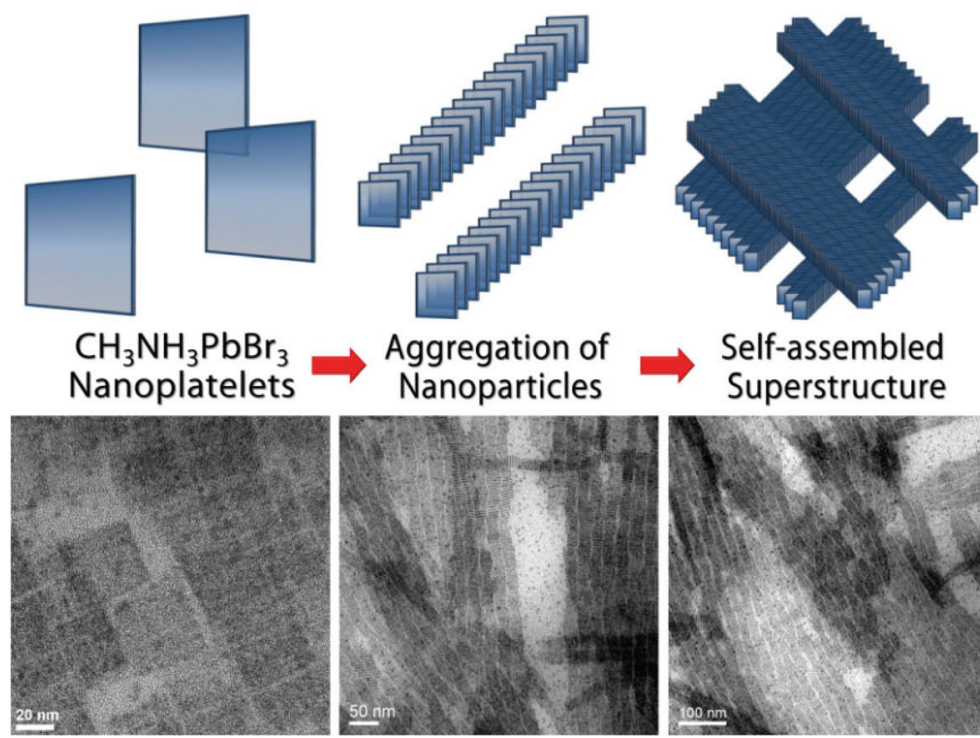

Self-assembled Superstructure
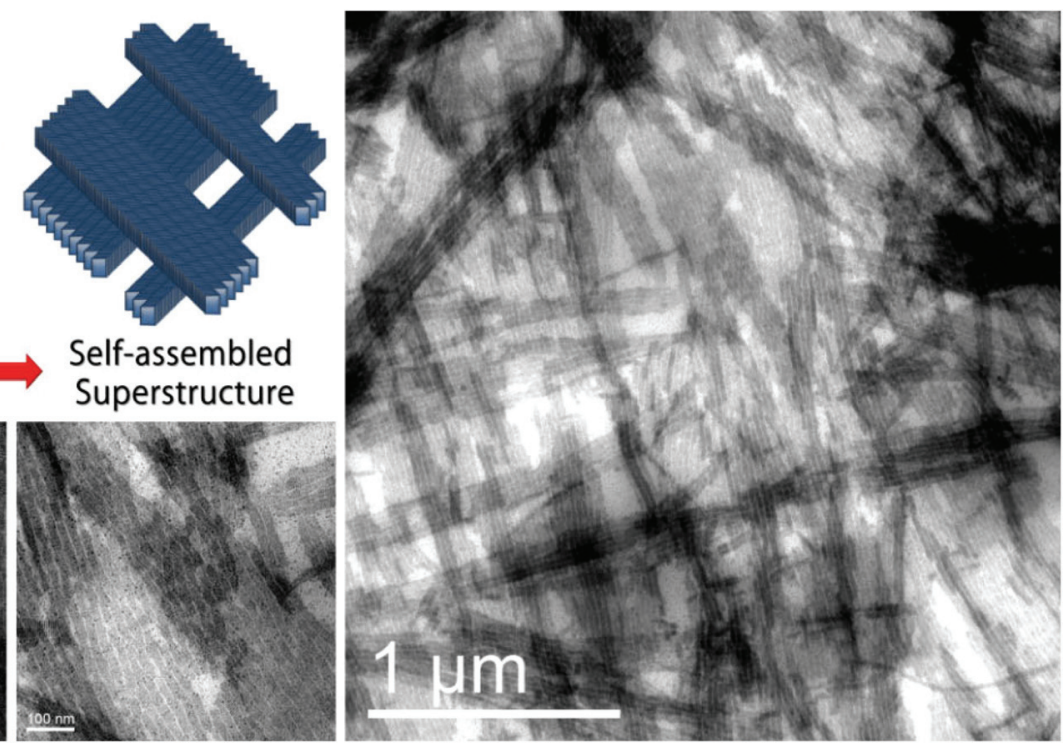

Fig. 3 Self-organization of $\mathrm{CH}_{3} \mathrm{NH}_{3} \mathrm{PbBr}_{3}$ nanoplatelets: from individual platelets to the stacking into wire-like structures, followed by bunching of wire-like superlattices.

evaporation or simply by storing concentrated dispersions, a light-yellow precipitate of wire-like superlattices is formed by face-to-face stacking of nanoplatelets (see Fig. 3). Oftentimes this self-organization involves the entire ensemble. We hypothesize that these superlattices are, in fact, analogues of Ruddlesden-Popper perovskite phases. Thin layers of
$\mathrm{CH}_{3} \mathrm{NH}_{3} \mathrm{PbBr}_{3}$ are separated by oleylammonium cations, leading to an overall superlattice composition of (oleyl$\left.\mathrm{NH}_{3}\right)_{2}\left(\mathrm{CH}_{3} \mathrm{NH}_{3}\right)_{n-1} \mathrm{~Pb}_{n} \mathrm{Br}_{3 n+1}$, where $n$ is the number of unit cells in the perovskite-like slab whose limits correspond to a fully 3D lattice of $\mathrm{CH}_{3} \mathrm{NH}_{3} \mathrm{PbBr}_{3}$ (at $n=\infty$ ) and a single-layer $2 \mathrm{D}$ lattice of (oleyl- $\left.\mathrm{NH}_{3}\right)_{2} \mathrm{PbBr}_{4}($ at $n=1)$. XRD reflections at $2 \theta$ 
values of $11.5^{\circ}(d=7.68 \AA)$ and $13.44^{\circ}(d=6.58 \AA)$ (Fig. $2 \mathrm{~g}$ ), both corresponding to distances larger than the unit cell $(5.93 \AA$ ) , indicate a superlattice spacing of $\sim 54 \AA$, fully consistent with TEM data.

From the absorption peak position of $\sim 450 \mathrm{~nm}$, we estimate a value of $n=3$ based on previous studies of layered lead bromide perovskites. ${ }^{27,45}$ The inter-slab distance of $54 \AA$ can thus be interpreted as the sum of two oleylamine molecules and three unit cells of a perovskite slab. Note that bulk, fully 3-dimensional $\mathrm{CH}_{3} \mathrm{NH}_{3} \mathrm{PbBr}_{3}$ is luminescent with $\mathrm{PL}$ at $\sim 570 \mathrm{~nm},{ }^{10}$ while fully 2-dimensional $\left(\mathrm{RNH}_{3}\right)_{2} \mathrm{PbBr}_{4}$ compounds emit at $400-420 \mathrm{~nm} .{ }^{44}$

\section{Stability and durability of $\mathrm{CH}_{3} \mathrm{NH}_{3} \mathrm{PbX}_{3}$ NCs}

Colloidal lead halide perovskites are much more chemically labile than more conventional colloidal quantum dots of metal chalcogenides. ${ }^{50}$ The comparison of $\mathrm{CH}_{3} \mathrm{NH}_{3} \mathrm{PbX}$ NCs against $\mathrm{CsPbX}_{3} \mathrm{NCs}$ (as in our recent study ${ }^{41}$ ) demonstrates the much lower stability of the former. All characterization presented in this communication concerning $\mathrm{CH}_{3} \mathrm{NH}_{3} \mathrm{PbX}_{3} \mathrm{NCs}$ was conducted on rather "dirty" samples, as for example those precipitated from the crude solution and redispersed in toluene. Additional purification steps, conducted either in air or under an inert-gas atmosphere, had always led to decomposition of the NCs. Non-purified samples, in contrast, can maintain their bright PL for weeks or months after synthesis.

Clearly, a large excess of capping ligands is required to maintain the chemical integrity of $\mathrm{CH}_{3} \mathrm{NH}_{3} \mathrm{PbX}_{3}$ NCs. Humidity is a factor contributing to the severe instability of $\mathrm{CH}_{3} \mathrm{NH}_{3} \mathrm{PbX}_{3},{ }^{51}$ causing the release of $\mathrm{CH}_{3} \mathrm{NH}_{2}$ or $\mathrm{PbI}_{2}$, or even the formation of $\left(\mathrm{CH}_{3} \mathrm{NH}_{3}\right)_{4} \mathrm{PbI}_{6} \cdot 2 \mathrm{H}_{2} \mathrm{O}{ }^{52}$ Satisfactory retention of the chemical integrity of $\mathrm{MAPbX}_{3}$ NCs in the presence of an excess of ligands, despite inherently high surfaceto-volume ratios, can be ascribed to the highly hydrophobic nature of the capping layer. Another source of instability is the low energy of formation of $\mathrm{CH}_{3} \mathrm{NH}_{3} \mathrm{PbX}_{3}$ compounds, ${ }^{53}$ leading to slow irreversible dissociation into $\mathrm{CH}_{3} \mathrm{NH}_{3} \mathrm{X}$ or $\mathrm{CH}_{3} \mathrm{NH}_{2}+\mathrm{HX}$, with all volatile products in either case, and $\mathrm{PbX}_{2}$. A ligand-passivated surface may inhibit this decomposition, explaining the satisfactory stability of $\mathrm{CH}_{3} \mathrm{NH}_{3} \mathrm{PbBr}_{3}$ NCs in a "dirty" state. The low melting point of hybrid and fully inorganic perovskite NCs leads to facile sintering in their solid state films, oftentimes readily observed in TEM images.

\section{Stimulated emission from $\mathrm{CH}_{3} \mathrm{NH}_{3} \mathrm{PbBr}_{3} \mathrm{NCs}$}

Upon pulsed excitation (400 nm, $100 \mathrm{fs}$ ), a low-threshold amplified spontaneous emission (ASE) is observed from a film of $\mathrm{CH}_{3} \mathrm{NH}_{3} \mathrm{PbBr}_{3}$ NCs on a glass substrate (Fig. 4). The ASE band is spectrally different from the PL emission: it has a narrower bandwidth of 7-9 nm (compared to the PL FWHM of
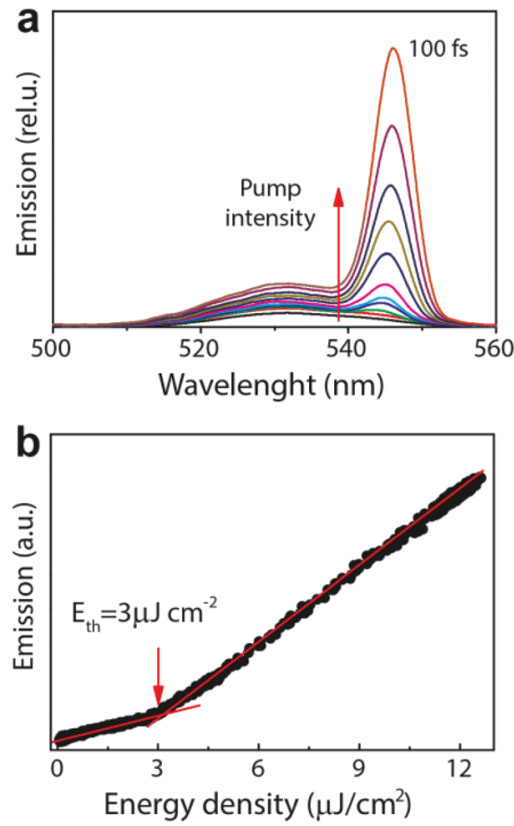

Fig. 4 Studies of lasing applications of $\mathrm{CH}_{3} \mathrm{NH}_{3} \mathrm{PbBr}_{3}$ perovskite nanowires: (a) amplified spontaneous emission (ASE) spectra of films prepared by a drop-casting technique from colloidal solution; (b) normalised ASE intensity versus energy density, and a linear fit intersection indicating a lasing threshold of $3 \pm 1 \mu \mathrm{J} \mathrm{cm}^{-2}$.

$20 \mathrm{~nm}$ ), and is red-shifted by almost $20 \mathrm{~nm}$ with respect to the PL maximum, presumably owing to the bi-excitonic nature of the optical gain. ${ }^{34,37}$ The threshold for building ASE is $\sim 3 \pm$ $1 \mu \mathrm{J} \mathrm{cm}^{-2}$, a factor of 2-3 lower than for $\mathrm{CsPbBr}_{3} \mathrm{NCs}^{, 54}$ when emitting at the nearly same wavelengths. However, an interesting difference is observed with regard to the emission relaxation. The $240 \mathrm{~ns}$ PL lifetime of $\mathrm{CH}_{3} \mathrm{NH}_{3} \mathrm{PbBr}_{3} \mathrm{NCs}$ is notably longer than the 5 ns lifetime of $\mathrm{CsPbBr}_{3} \mathrm{NCs}$, both in solution and under similar excitation intensities. For $\mathrm{CsPbBr}_{3} \mathrm{NCs}$, PL lifetime is invariant in solution and fluency-dependent in compact films (Fig. S2†). This can be explained by excitonexciton interactions, leading to faster relaxation with increasing pumping fluency. For $\mathrm{CH}_{3} \mathrm{NH}_{3} \mathrm{PbBr}_{3}$ nanowires, such behaviour is already seen in solution and may be explained by the co-existence of multiple excitons within the individual nanowire.

In summary, in this report we describe a new solutionphase synthesis of highly-luminescent $\mathrm{CH}_{3} \mathrm{NH}_{3} \mathrm{PbX}_{3}(\mathrm{X}=\mathrm{Br}$ and I) nanocrystals with cube, wire and platelet morphologies. We have shown that polar solvents such as DMF can be completely eliminated from the synthesis strategy, thus allowing the nucleation and growth to occur in a fully homogeneous medium. We observed self-organization of $\mathrm{CH}_{3} \mathrm{NH}_{3} \mathrm{PbBr}_{3}$ nanoplatelets into wire-like superlattices. We also assessed lasing properties of $\mathrm{CH}_{3} \mathrm{NH}_{3} \mathrm{PbBr}_{3}$ nanowires and observed low thresholds for ASE. On the practical side, we note that hybrid organic-inorganic perovskite nanostructures suffer from severe instability and cannot easily be isolated in a purified state without decomposition. Hence we suggest that 
future strategies on their synthesis and applications should focus on the development of surface passivation with multidentate ligands that do not desorb during purification or on their efficient encapsulation into polymer or inorganic matrices.

\section{Acknowledgements}

This work was supported by the European Comission via the Marie-Sklodowska Curie action Phonsi (H2020MSCA-ITN-642656) and by the ERC Starting Grant NANOSOLID (GA no. 306733). We thank Prof. Manfred Fiebig and his research group for granting us access to their femtosecond laser apparatus and for technical assistance, and Dr Nicholas Stadie for reading the manuscript. We also acknowledge the support of the Scientific Center for Optical and Electron Microscopy (ETH Zürich) and the Empa Electron Microscopy Center.

\section{Notes and references}

1 M. Gratzel, Nat. Mater., 2014, 13, 838-842.

2 M. A. Green, A. Ho-Baillie and H. J. Snaith, Nat. Photonics, 2014, 8, 506-514.

3 N. G. Park, J. Phys. Chem. Lett., 2013, 4, 2423-2429.

4 H. Zhou, Q. Chen, G. Li, S. Luo, T. B. Song, H. S. Duan, Z. Hong, J. You, Y. Liu and Y. Yang, Science, 2014, 345, 542546.

5 I. Chung, B. Lee, J. He, R. P. Chang and M. G. Kanatzidis, Nature, 2012, 485, 486-489.

6 S. D. Stranks, G. E. Eperon, G. Grancini, C. Menelaou, M. J. Alcocer, T. Leijtens, L. M. Herz, A. Petrozza and H. J. Snaith, Science, 2013, 342, 341-344.

7 G. Xing, N. Mathews, S. Sun, S. S. Lim, Y. M. Lam, M. Gratzel, S. Mhaisalkar and T. C. Sum, Science, 2013, 342, 344-347.

8 W. Nie, H. Tsai, R. Asadpour, J. C. Blancon, A. J. Neukirch, G. Gupta, J. J. Crochet, M. Chhowalla, S. Tretiak, M. A. Alam, H. L. Wang and A. D. Mohite, Science, 2015, 347, 522-525.

9 Q. Dong, Y. Fang, Y. Shao, P. Mulligan, J. Qiu, L. Cao and J. Huang, Science, 2015, 347, 967-970.

10 D. Shi, V. Adinolfi, R. Comin, M. Yuan, E. Alarousu, A. Buin, Y. Chen, S. Hoogland, A. Rothenberger, K. Katsiev, Y. Losovyj, X. Zhang, P. A. Dowben, O. F. Mohammed, E. H. Sargent and O. M. Bakr, Science, 2015, 347, 519-522.

11 F. Zhang, H. Zhong, C. Chen, X. G. Wu, X. Hu, H. Huang, J. Han, B. Zou and Y. Dong, ACS Nano, 2015, 9, 4533-4542.

12 M. I. Saidaminov, A. L. Abdelhady, B. Murali, E. Alarousu, V. M. Burlakov, W. Peng, I. Dursun, L. Wang, Y. He, G. Maculan, A. Goriely, T. Wu, O. F. Mohammed and O. M. Bakr, Nat. Commun., 2015, 6, 7586, DOI: 10.1038/ ncomms8586.
13 N. J. Jeon, J. H. Noh, W. S. Yang, Y. C. Kim, S. Ryu, J. Seo and S. I. Seok, Nature, 2015, 517, 476-480.

14 G. E. Eperon, S. D. Stranks, C. Menelaou, M. B. Johnston, L. M. Herz and H. J. Snaith, Energy Environ. Sci., 2014, 7, 982.

15 M. Liu, M. B. Johnston and H. J. Snaith, Nature, 2013, 501, 395-398.

16 L. Dou, Y. M. Yang, J. You, Z. Hong, W. H. Chang, G. Li and Y. Yang, Nat. Commun., 2014, 5, 5404.

17 M. I. Saidaminov, V. Adinolfi, R. Comin, A. L. Abdelhady, W. Peng, I. Dursun, M. Yuan, S. Hoogland, E. H. Sargent and O. M. Bakr, Nat. Commun., 2015, 6, 8724, DOI: 10.1038/ncomms9724.

18 Y. Fang, Q. Dong, Y. Shao, Y. Yuan and J. Huang, Nat. Photonics, 2015, 9, 679-686.

19 G. Maculan, A. D. Sheikh, A. L. Abdelhady, M. I. Saidaminov, M. A. Haque, B. Murali, E. Alarousu, O. F. Mohammed, T. Wu and O. M. Bakr, J. Phys. Chem. Lett., 2015, 6, 3781-3786.

20 Y. L. Guo, C. Liu, H. Tanaka and E. Nakamura, J. Phys. Chem. Lett., 2015, 6, 535-539.

21 S. Yakunin, M. Sytnyk, D. Kriegner, S. Shrestha, M. Richter, G. J. Matt, H. Azimi, C. J. Brabec, J. Stangl, M. V. Kovalenko and W. Heiss, Nat. Photonics, 2015, 9, 444-449.

22 Z. K. Tan, R. S. Moghaddam, M. L. Lai, P. Docampo, R. Higler, F. Deschler, M. Price, A. Sadhanala, L. M. Pazos, D. Credgington, F. Hanusch, T. Bein, H. J. Snaith and R. H. Friend, Nat. Nanotechnol., 2014, 9, 687-692.

23 O. A. Jaramillo-Quintero, R. S. Sanchez, M. Rincon and I. Mora-Sero, J. Phys. Chem. Lett., 2015, 6, 18831890.

24 Y. H. Kim, H. Cho, J. H. Heo, T. S. Kim, N. Myoung, C. L. Lee, S. H. Im and T. W. Lee, Adv. Mater., 2015, 27, 1248-1254.

25 S. D. Stranks and H. J. Snaith, Nat. Nanotechnol., 2015, 10, 391-402.

26 E. R. Dohner, A. Jaffe, L. R. Bradshaw and H. I. Karunadasa, J. Am. Chem. Soc., 2014, 136, 1315413157.

27 J. A. Sichert, Y. Tong, N. Mutz, M. Vollmer, S. Fischer, K. Z. Milowska, R. García Cortadella, B. Nickel, C. Cardenas-Daw, J. K. Stolarczyk, A. S. Urban and J. Feldmann, Nano Lett., 2015, 15, 6521-6527.

28 S. T. Ha, X. Liu, Q. Zhang, D. Giovanni, T. C. Sum and Q. Xiong, Adv. Opt. Mater., 2014, 2, 838-844.

29 L. C. Schmidt, A. Pertegas, S. Gonzalez-Carrero, O. Malinkiewicz, S. Agouram, G. Minguez Espallargas, H. J. Bolink, R. E. Galian and J. Pérez-Prieto, J. Am. Chem. Soc., 2014, 136, 850-853.

30 D. Di, K. P. Musselman, G. Li, A. Sadhanala, Y. Ievskaya, Q. Song, Z. K. Tan, M. L. Lai, J. L. MacManus-Driscoll, N. C. Greenham and R. H. Friend, J. Phys. Chem. Lett., 2015, 6, 446-450.

31 Y. Fu, F. Meng, M. B. Rowley, B. J. Thompson, M. J. Shearer, D. Ma, R. J. Hamers, J. C. Wright and S. Jin, J. Am. Chem. Soc., 2015, 137, 5810-5818. 
32 S. Gonzalez-Carrero, G. M. Espallargas, R. E. Galian and J. Perez-Prieto, J. Mater. Chem. A, 2015, 3, 14039-14045.

33 S. Gonzalez-Carrero, R. E. Galian and J. Pérez-Prieto, J. Mater. Chem. A, 2015, 3, 9187-9193.

34 S. González-Carrero, R. E. Galian and J. Pérez-Prieto, Part. Part. Syst. Charact., 2015, 32, 709-720.

35 H. Huang, A. S. Susha, S. V. Kershaw, T. F. Hung and A. L. Rogach, Adv. Sci., 2015, 2, 1500194.

36 D. M. Jang, K. Park, D. H. Kim, J. Park, F. Shojaei, H. S. Kang, J. P. Ahn, J. W. Lee and J. K. Song, Nano Lett., 2015, 15, 5191-5199.

37 P. Tyagi, S. M. Arveson and W. A. Tisdale, J. Phys. Chem. Lett., 2015, 6, 1911-1916.

38 A. B. Wong, M. Lai, S. W. Eaton, Y. Yu, E. Lin, L. Dou, A. Fu and P. Yang, Nano Lett., 2015, 15, 5519-5524.

39 F. Zhu, L. Men, Y. Guo, Q. Zhu, U. Bhattacharjee, P. M. Goodwin, J. W. Petrich, E. A. Smith and J. Vela, ACS Nano, 2015, 9, 2948-2959.

40 S. Zhuo, J. Zhang, Y. Shi, Y. Huang and B. Zhang, Angew. Chem., Int. Ed., 2015, 54, 5693-5696.

41 L. Protesescu, S. Yakunin, M. I. Bodnarchuk, F. Krieg, R. Caputo, C. H. Hendon, R. X. Yang, A. Walsh and M. V. Kovalenko, Nano Lett., 2015, 15, 3692-3696.

42 G. Nedelcu, L. Protesescu, S. Yakunin, M. I. Bodnarchuk, M. J. Grotevent and M. V. Kovalenko, Nano Lett., 2015, 15, 5635-5640.

43 Q. A. Akkerman, V. D’Innocenzo, S. Accornero, A. Scarpellini, A. Petrozza, M. Prato and L. Manna, J. Am. Chem. Soc., 2015, 137, 10276-10281.
44 L. Dou, A. B. Wong, Y. Yu, M. Lai, N. Kornienko, S. W. Eaton, A. Fu, C. G. Bischak, J. Ma, T. Ding, N. S. Ginsberg, L. W. Wang, A. P. Alivisatos and P. Yang, Science, 2015, 349, 1518-1521.

45 Y. Tabuchi, K. Asai, M. Rikukawa, K. Sanui and K. Ishigure, J. Phys. Chem. Solids, 2000, 61, 837-845.

46 M. Era, S. Morimoto, T. Tsutsui and S. Saito, Appl. Phys. Lett., 1994, 65, 676.

47 T. Kondo, T. Azuma, T. Yuasa and R. Ito, Solid State Commun., 1998, 105, 253-255.

48 G. Lanty, K. Jemli, Y. Wei, J. Leymarie, J. Even, J. S. Lauret and E. Deleporte, J. Phys. Chem. Lett., 2014, 5, 39583963.

49 D. B. Mitzi, K. Chondroudis and C. R. Kagan, IBM J. Res. Dev. , 2001, 45, 29-45.

50 D. V. Talapin, J.-S. Lee, M. V. Kovalenko and E. V. Shevchenko, Chem. Rev., 2009, 110, 389-458.

51 G. Niu, X. Guo and L. Wang, J. Mater. Chem. A, 2015, 3, 8970-8980.

52 A. Halder, D. Choudhury, S. Ghosh, A. S. Subbiah and S. K. Sarkar, J. Phys. Chem. Lett., 2015, 6, 31803184.

53 Y.-Y. Zhang, S. Chen, P. Xu, H. Xiang, X.-G. Gong, A. Walsh and S.-H. Wei, 2015, arXiv preprint arXiv:1506. 01301.

54 S. Yakunin, L. Protesescu, F. Krieg, M. I. Bodnarchuk, G. Nedelcu, M. Humer, G. De Luca, M. Fiebig, W. Heiss and M. V. Kovalenko, Nat. Commun., 2015, 6, 8056, DOI: 10.1038/ncomms9056. 